\title{
A INFORMATIVIDADE NO PROCESSO DE ESCRITA ARGUMENTATIVA ESCOLAR: ELABORAÇÃO DE INSTRUMENTOS DIDÁTICOS A PARTIR DE ARTICULAÇÕES TEÓRICO- METODOLÓGICAS
}

\author{
INFORMATIVITY IN ARGUMENTATIVE WRITING PROCESS IN \\ SCHOOL: ELABORATION OF PEDAGOGICAL INSTRUMENTS \\ FROM THEORETICAL-METHODOLOGICAL ARTICULATIONS
}

Aline Rubiane Arnemann ${ }^{1}$

\begin{abstract}
RESUMO: Este artigo objetiva compartilhar discussões e reflexões acerca do critério de informatividade, com base em Arnemann (2020), elucidando contribuições do uso da informatividade na elaboração de instrumentos didáticos para ancorar o processo de escrita escolar. Para tal, abordamos noções elementares acerca da informatividade, a saber os graus baixo, médio e alto de informatividade e as definições que assumimos para os termos "dado" e "novo". Atreladas a essas noções, exploramos as recontextualizações realizadas do cenário científico para o escolar que culminaram na elaboração de quadros, quais sejam: Quadro para identificação de uso de estratégias argumentativas e Quadro autoavaliativo sobre o processo de produção textual, utilizados pelos participantes de pesquisa, Arnemann (2020), ao longo das produções textuais que desenvolveram e entre as etapas de escrita de cada produção; Levantamento de informações (novas e dadas) na produção textual e Quadro para sinalização da informatividade, decorrentes dos resultados de Arnemann (2020); e Mapeamento do interlocutor, reflexão posterior. Tais quadros advém de uma proposta teórico-metodológica e se configuram como instrumento e proposta didática, visto que tem o potencial de subsidiar ações discentes e docentes no processo de escrita argumentativa, diante dos desafios que quem estuda, ensina e/ou aprende enfrenta em relação ao texto.
\end{abstract}

PALAVRAS-CHAVE: Informatividade. Instrumento e proposta didática. Escrita argumentativa escolar.

ABSTRACT: This article aims to discuss and reflect on the criterion of informativity based on Arnemann (2020), elucidating contributions of the use of informativity in the development of teaching instruments to anchor the school students' writing process. Thus, we approach fundamental notions on informativity, namely the low, medium, and high degrees of informativity and the definitions we consider for the terms "given" and "new". Taking these notions into account, we explore the recontextualization from science to school context which culminated in the elaboration of the following frameworks: Framework for identifying the use of argumentative strategies and Self-evaluation framework on the textual production process,

\footnotetext{
${ }^{1}$ Doutora em Letras. arnemannaline@gmail.com
} 


\section{PERcursos Linguísticos • Vitória (ES) •v. 11 •n. 29 • 2021 • ISSN: 2236-2592 • Dossiê temático $\bullet O$ texto na pesquisa e no ensino: conhecimentos, práticas e desafios na contemporaneidade •}

which were used by the research participants, Arnemann (2020), throughout the writing productions they developed and between the writing stages of each production; Survey for information (new and given) in the writing production and Framework for signposting informativity, from the results of Arnemann (2020); and Interlocutor mapping, elaborated after the results. Such frameworks come from a theoretical-methodological proposal and are configured as instrument and pedagogical proposal, since they have the potential to support students and teachers' actions in the argumentative writing process, given the challenges in relation to the text faced by those who study, teach, and/or learn.

KEYWORDS: Informativity. Instrument and teaching proposal. Argumentative writing in school.

\section{Considerações iniciais}

Neste espaço, situamo-nos na posição de interlocutores diante do questionamento presente na chamada à qual este artigo se inscreve: “quais propostas teórico-metodológicas ou quais propostas didáticas configuram desafios para quem tem o texto como objeto de pesquisa e/ou de ensino na contemporaneidade?". Nesse sentido, a fim de contribuir com reflexões e com o desencadeamento de novas reflexões acerca da referida problemática, e considerando a natureza multifacetada e complexa do texto, discutimos, aqui, uma interface de pesquisa e ensino do texto. Dessa maneira, este artigo se inscreve como uma contribuição para o enfrentamento de um dos desafios atuais do trabalho com o texto em sala de aula no Brasil: as propostas teórico-metodológicas.

A definição desse ponto de vista de escrita se deve ao marco de origem desta discussão: a tese de doutorado Informatividade na sala de aula: o emprego de informações na construção de argumentos (ARNEMANN, 2020). Tal produção é resultado da preocupação com o ensino do texto em sala de aula e da percepção acerca da extrema necessidade de relação entre teoria e prática, pois somente essa articulação pode conferir efetividade na mediação entre conhecimentos científicos ou escolares e conhecimentos cotidianos, contribuindo para a aprendizagem do estudante.

Nesse sentido, com vistas a situar nosso interlocutor acerca da necessidade de resgate à referida tese neste texto, abordamos sumariamente seu contexto de desenvolvimento. Tal estudo é resultado de uma parceria ${ }^{2}$ entre Instituição de Ensino Superior - representada pelo Programa de Pós-Graduação em Letras (PPGL) da Universidade Federal de Santa Maria (UFSM) - e uma

\footnotetext{
${ }^{2}$ Autorizada pelo Comitê de Ética em Pesquisa e registrada sob o CAAE 78737817.0.0000.5346.
} 


\section{PERcursos Linguísticos • Vitória (ES) •v. 11 •n. 29 • 2021 • ISSN: 2236-2592 • Dossiê temático $\bullet O$ texto na pesquisa e no ensino: conhecimentos, práticas e desafios na contemporaneidade •}

Instituição de Ensino Básico - representada por uma escola pública situada no município de Santa Maria, RS.

Essa parceria propiciou a realização de uma Pesquisa-Ação - no viés de Thiollent (2011) e Burns (2010) - cujos envolvidos foram: a pesquisadora professora ${ }^{3}$, o professor titular ${ }^{4}$ da disciplina de Língua Portuguesa das turmas de terceiro ano de Ensino Médio da escola já mencionada e uma dessas turmas, identificada como $3^{\circ} \mathrm{C}$. Assim, no decorrer dos meses de junho a dezembro de 2018, a pesquisadora professora desenvolveu um processo de ensino de produção textual argumentativa com os terceiranistas em questão, com a colaboração do professor titular.

Para dinamizar o referido processo, foram realizadas duas grandes articulações: uma teórica e outra metodológica. A primeira envolveu a Linguística do Texto, com ênfase no critério de informatividade, os postulados da Teoria da Argumentação, de Perelman e Olbrechts-Tyteca (2014), a perspectiva sociointeracionista de ensino, de Lev S. Vygotsky, e as contribuições de Mikhail Bakhtin acerca da interação verbal e do dialogismo. A segunda teve a Pesquisa-Ação como eixo central, à qual foram acomodadas: a perspectiva genebrina de gêneros textuais, de Dolz e Schneuwly (2004), a sequência didática, de Dolz, Noverraz e Schneuwly (2004), o Desenvolvimento Profissional Corresponsável (DPC), de Richter (2008), Freitag e Richter (2015) e Bom Camilo (2017, 2020) e a pergunta problematizadora, de Freire e Faundez (1985).

Essas duas articulações, além de sustentarem o desenvolvimento do estudo em si e a elaboração de categorias de análise inerentes à cientificidade que a pesquisa requer, viabilizaram um constructo teórico-prático que não se restringe ao espaço de estudo acadêmico do texto. Indo além, contempla essa possibilidade e, sobretudo, propicia o uso efetivo de instrumentos didáticos para o ensino do texto em sala de aula, em especial na escola básica.

Convém pontuar que realizamos essas contextualizações com a finalidade de situar o leitor acerca do universo de pesquisa e do fulcro das discussões e reflexões que tecemos, nas seções subsequentes, acerca e a partir de um dos resultados da referida tese, o qual diz respeito à sinalização da informatividade, em especial ao uso de quadros - como instrumento didático - no trabalho com esse critério de textualidade no ensino de escrita argumentativa na escola. É por meio desse ponto que nos inscrevemos no espaço de discussão referente à proposta teórico-

\footnotetext{
${ }^{3}$ Autora deste estudo e da tese em comento, a qual, no momento de realização da geração de dados, representava a UFSM.

${ }^{4}$ Professor representante da Escola Estadual de Educação Básica Professora Margarida Lopes.
} 


\section{PERcursos Linguísticos • Vitória (ES) •v. 11 •n. 29 • 2021 • ISSN: 2236-2592 • Dossiê temático $\bullet O$ texto na pesquisa e no ensino: conhecimentos, práticas e desafios na contemporaneidade •}

metodológicas e/ou didáticas desafios que desafiam pesquisadores, professores e estudantes de textos hoje, no Brasil.

\section{O critério de informatividade: disposições teórico-metodológicas}

Iniciamos as discussões correspondentes ao tratamento teórico pelo critério de informatividade, proposto por Beaugrande e Dressler (1981), haja vista que tal tema tem posição essencial neste estudo. Nesse sentido, resgatamos uma comparação do texto com um tecido, muito oportuna aos estudiosos de texto, em especial, da Linguística do Texto. Esse paralelo se deve, pois o tecido somente assume tal natureza a partir da costura dos fios, os quais, isolados, são apenas fios. De semelhante maneira, o texto assume sua natureza a partir da articulação de seus elementos constitutivos, de modo que um elemento sozinho não confere textualidade ao texto. Esperamos que essa analogia, ao nosso interlocutor, inscreva-se com um grau baixo de informatividade, pois não traz novidades, mas informações dadas, ou seja, já de conhecimento.

Nessa continuidade, Beaugrande e Dressler (1981) defendem que, na constituição de um texto, entra em curso a operação de sete critérios de textualidade, quais sejam: coesão, coerência, intencionalidade, aceitabilidade, situacionalidade, intertextualidade e informatividade. Pontuamos que focalizar o estudo do texto a partir da informatividade não desconsidera a existência dos demais critérios (todos são fundamentais). Essa afirmação se vale para qualquer um dos critérios que seja tomado como foco (de investigação e/ou de ensino). Esperamos que essa seja, também, uma observação de grau baixo de informatividade ao nosso interlocutor.

Quando assumimos um foco, é possível aprofundar e aprimorar conhecimentos e saberes em relação ao que foi selecionado, além de estabelecer (novas) relações. Nesse caso, no que diz respeito ao critério de informatividade, recuperamos discussões que podem assumir um grau alto de informatividade para alguns interlocutores, diante de seu caráter de novidade e, por conseguinte, talvez demande maior processamento textual. Para outros, que já têm conhecimento acerca de determinadas noções, pode assumir um grau médio de informatividade, favorecendo, assim, um balanceamento entre informações novas e dadas que contribuiu com a construção de sentido. Esperamos não contemplar o grau baixo de informatividade para a grande maioria dos interlocutores deste texto.

Beaugrande e Dressler (1981) dispõem que a informatividade diz respeito à apresentação de informações novas em determinada extensão textual. Parece simples, 


\section{PERcursos Linguísticos • Vitória (ES) •v. 11 •n. 29 • 2021 • ISSN: 2236-2592 • Dossiê temático $\bullet O$ texto na pesquisa e no ensino: conhecimentos, práticas e desafios na contemporaneidade •}

entretanto essa definição assume complexidade, visto que a informatividade se trata de um fenômeno de linguagem no qual operam questões de ordem contextual e social. Explicamos: uma informação pode assumir um grau maior ou menor de novidade de acordo com cada indivíduo, que tem sua história, está inserido em determinado ambiente sociocultural e nele realiza determinadas interações com outros sujeitos, mediante distintos gêneros textuais.

Assim, uma mesma informação pode assumir uma enorme obviedade para uma pessoa, ao passo que, para outra, pode ser estapafúrdia. Em casos de obviedade, o interlocutor processa rapidamente a informação. Todavia, quando em excesso, as informações dadas podem causar desinteresse, pois a novidade é escassa. Por outro lado, a incompreensão requer um processamento maior da informação e, se não resolvida, pode ocasionar, também, desinteresse, uma vez que o interlocutor não consegue construir sentidos para o texto.

Essas elucidações mostram um excerto da complexidade da interação entre as informações e seus usuários. Isso faz muito sentido no contexto atual, com a ascensão digital global e com o fenômeno das Fake News, o qual tem acometido um número elevadíssimo de indivíduos. As pessoas têm revelado dificuldades e, em alguns casos, barreiras com o uso de informações. Por isso, nunca foi tão essencial o trabalho com informações e, aqui, a informatividade assume seu lócus de contribuição.

Desse modo, realizamos uma espécie de pingue-pongue entre as disposições dos teóricos proponentes do critério de informatividade, Beaugrande e Dressler (1981), e nossas contribuições, conforme as pistas textuais já indiciaram. Tomamos esse posicionamento a fim de conferir um tratamento teórico-prático acerca do critério de informatividade e alcançar, aqui, um dos postulados de Koch e Elias $(2014$, p.34) no que se refere às estratégias de escrita: o “ 'balanceamento' entre informações explícitas e implícitas; entre informações 'novas' e 'dadas', levando em conta o compartilhamento de informações com o leitor e o objetivo da escrita".

Conforme anunciamos, o critério de informatividade de um texto pode ser observado em uma escala de graus de informatividade: grau baixo - presença de informações previsíveis e dadas; grau médio - balanceamento entre informações novas e dadas; e grau alto predomínio de informações novas e imprevisíveis, de acordo com Beaugrande e Dressler (1981). Segundo os autores em comento, o grau médio de informatividade é o mais favorável para o estabelecimento da comunicação humana.

Desde a proposição do critério em questão até a atualidade, tivemos poucas iniciativas referentes ao uso da informatividade no contexto de ensino e aprendizagem de Língua Portuguesa, em especial de produção textual escrita nem alcançando, ainda, a produção textual 


\section{PERcursos Linguísticos • Vitória (ES) •v. 11 •n. 29 • 2021 • ISSN: 2236-2592 • Dossiê temático $\bullet O$ texto na pesquisa e no ensino: conhecimentos, práticas e desafios na contemporaneidade •}

oral e de textos multissemióticos - pauta para investigações vindouras. A enorme maioria das pesquisas que investigaram a informatividade se dedicaram a identificar o grau de informatividade de textos escritos escolares, na perspectiva do texto como um produto pronto e acabado. Isso se deve, também, em nosso ponto de vista à existência de uma lacuna teórica que viabilize o uso da informatividade no trabalho com o texto processo.

Nesse sentido, tal lacuna, atrelada a nossa preocupação com o ensino de escrita argumentativa em sala de aula, inscreveu-se como um espaço de oportunidade para investigar alternativas de trabalho com a informatividade. Assim, em Arnemann (2020), algumas perguntas impulsionaram nossas ações: como definir o que diz respeito a uma informação nova e o que se refere a uma informação dada? ${ }^{5}$ Como o produtor de um texto identifica quem é seu (possível) interlocutor, para, então, ponderar acerca das informações que pode utilizar no seu texto - quais pode deixar na implicitude e quais deve levar à explicitude? Como o professor pode auxiliar os estudantes a identificar o que é uma informação nova e o que é uma informação dada? Como o docente pode auxiliar os estudantes no processo de busca, seleção, apresentação e interpretação de informação?

Resgatamos as perguntas, a fim de acentuar que com elas inicia o conhecimento, pois, conforme expõem Freire e Faundez (1985, p. 24): "no ensino esqueceram-se das perguntas, tanto o professor como o aluno esqueceram-nas, e no meu entender todo conhecimento começa pela pergunta". Ademais, registramos que o pesquisador e o professor necessitam ser "perguntadores" e, na posição em que estão, ensinar os sujeitos sociais - especificamente, os estudantes - a perguntar. Nosso interlocutor pode estar questionando: qual a relação entre informatividade e as perguntas e por que tamanha ênfase dedicada às perguntas? Explicamos: a partir do momento em que o sujeito social se torna um "perguntador", ou um aprimorado "perguntador", há um processo anterior, que é o de tomada de consciência de seu lugar no e com o mundo e do potencial de sua atuação ativa nos meios em que interage. $\mathrm{O}$ sujeito "perguntador" tem, diante de si, a capacidade de questionar as informações e não somente no sentido de serem verdadeiras ou falsas, o que já é um avanço de grande valia, como também de questionar a finalidade do uso, a escolha das informações que foram para o plano explícito e aquelas que foram ocultadas, dentre inúmeras outras operações de pergunta em relação às informações.

\footnotetext{
${ }^{5}$ Beaugrande e Dressler (1981) dispõem que o interlocutor é responsável por definir o que é novo ou dado a ele, visto que assume a posição de receber a informação.
} 


\section{PERcursos Linguísticos • Vitória (ES) •v. 11 •n. 29 • 2021 • ISSN: 2236-2592 • Dossiê temático $\bullet O$ texto na pesquisa e no ensino: conhecimentos, práticas e desafios na contemporaneidade •}

Esse direcionamento à pergunta foi necessário no ensino da escrita argumentativa escolar a partir do viés da informatividade, pois os estudantes, participantes de pesquisa, demandaram tomar decisões em relação ao uso de informações em suas produções textuais. Com isso, pontuamos também que, para alcançar a possibilidade de trabalho com a informatividade no texto processo, com vistas a contribuir com um grupo social, foi e é fundamental aproximar teorias e métodos. A pergunta, portanto, inscreve-se como um método.

Retornando às perguntas que impulsionaram a referida pesquisa, exploramos as ações decorrentes, que se materializaram de diferentes maneiras, seja nas intervenções em sala de aula, nos textos e na elaboração de quadros que assumem uma funcionalidade de instrumento didático, ou seja, que possam ser utilizados em contextos de ensino. Iniciamos pela exposição de um deles - aqui elaborado a partir da reflexão acerca das ações realizadas - que se volta a auxiliar o produtor do texto a mapear seu (possível) interlocutor:

Quadro 1 - Mapeamento do interlocutor

\begin{tabular}{|c|c|c|c|}
\hline \multicolumn{2}{|c|}{$\begin{array}{l}\text { Possibilidades de perguntas } \\
\text { que o produtor pode realizar } \\
\text { a si em relação ao (possível) } \\
\text { interlocutor: }\end{array}$} & $\begin{array}{l}\text { Quais noções as respostas a essas perguntas } \\
\text { fornecem ao produtor de texto? }\end{array}$ & $\begin{array}{l}\text { Perfil de informações } \\
\text { de interesse do } \\
\text { (possível) } \\
\text { interlocutor: }\end{array}$ \\
\hline$\cdot \cong$ & 1. Onde mora? & $\begin{array}{l}\text { Localização geográfica: informações de } \\
\text { interesse para os habitantes locais. }\end{array}$ & \multirow{7}{*}{$\begin{array}{l}\text { As respostas - que } \\
\text { podem não ser exatas } \\
- \text { dessas perguntas } \\
\text { auxiliam o produtor a } \\
\text { mapear o interlocutor, } \\
\text { conferindo um perfil } \\
\text { de informações que } \\
\text { podem ser de } \\
\text { interesse dele. } \\
\text { Pontuamos que essas } \\
\text { respostas podem } \\
\text { auxiliar a mapear um } \\
\text { interlocutor, } \\
\text { particularmente, ou } \\
\text { um grupo de } \\
\text { interlocutores. }\end{array}$} \\
\hline$\underset{\substack{0 \\
0}}{0}$ & $\begin{array}{l}\text { 2.Com quem } \\
\text { interage? }\end{array}$ & $\begin{array}{l}\text { Contexto de interação: informações de } \\
\text { interesse para determinados grupos sociais. }\end{array}$ & \\
\hline 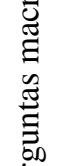 & $\begin{array}{l}\text { 3.O que faz em seu } \\
\text { dia a dia? }\end{array}$ & $\begin{array}{l}\text { Contexto de trabalho, estudo e/ou lazer: } \\
\text { informações de interesse para atividades } \\
\text { obrigatórias ou eletivas de determinados } \\
\text { grupos sociais. }\end{array}$ & \\
\hline ¿े & $\begin{array}{l}\text { 4.O que desperta } \\
\text { interesse? }\end{array}$ & $\begin{array}{l}\text { Assuntos: informações que podem atrair a } \\
\text { atenção do interlocutor. }\end{array}$ & \\
\hline \multirow{3}{*}{ 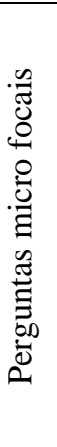 } & $\begin{array}{l}\text { 5.Quais informações } \\
\text { o interlocutor pode já } \\
\text { saber e que outras } \\
\text { podem ser novidade? }\end{array}$ & $\begin{array}{l}\text { No âmbito de cada um dos tópicos anteriores, o } \\
\text { que meu (possível) interlocutor já sabe e o que } \\
\text { pode ser novidade? }\end{array}$ & \\
\hline & $\begin{array}{l}6.0 \text { que o interlocutor } \\
\text { espera que seja } \\
\text { resgatado? }\end{array}$ & $\begin{array}{l}\text { Na esfera de informações compartilhadas, isto } \\
\text { é, de conhecimento de produtor e interlocutor, } \\
\text { o que o interlocutor espera que o produtor } \\
\text { resgate? }\end{array}$ & \\
\hline & $\begin{array}{l}7 . \mathrm{O} \text { que o interlocutor } \\
\text { espera encontrar no } \\
\text { âmbito da novidade? }\end{array}$ & $\begin{array}{l}\mathrm{Na} \text { abrangência de informações novas, o que o } \\
\text { interlocutor espera que o produtor informe? }\end{array}$ & \\
\hline
\end{tabular}

Fonte: Elaborado pela autora deste artigo.

O quadro apresentado sistematiza perguntas e noções que podem ser utilizadas para auxiliar o produtor de qualquer texto - desde que claros os objetivos de ensino e de aprendizagem - a identificar informações de interesse do interlocutor que tem em vista, ou seja, pode ser empregado em diferentes situações. Por intermédio do uso dessa ferramenta, o 


\section{PERcursos Linguísticos • Vitória (ES) •v. 11 •n. 29 • 2021 • ISSN: 2236-2592 • Dossiê temático $\bullet O$ texto na pesquisa e no ensino: conhecimentos, práticas e desafios na contemporaneidade •}

produtor de um texto precisa mobilizar sua atenção voluntária - uma das funções psicológicas superiores, a qual é, consoante Luria (1981, p. 168), "manifestada como a capacidade que tem a pessoa de verificar o seu próprio comportamento" - quando se volta ao seu interlocutor, realizando o que caracterizamos como mapeamento do interlocutor.

Trabalhar com o mapeamento do interlocutor ampara o autor do texto, ao fornecer indícios de onde e quais informações pode buscar para utilizar em sua produção. Nesse sentido, entra em cena outro aspecto que também pode subsidiar o autor do texto: a natureza da informação, a qual o auxilia a identificar uma informação (com maior precisão) em outros textos e ponderar qual natureza se inscreve como mais adequada à realização da interpretação ou mais propensa a convencer o interlocutor. Vale destacar que, por vezes, é necessário que o pesquisador e/ou o professor, dependendo do grupo social com o qual esteja interagindo, auxilie no sentido de propor e realizar atividades que forneçam base para o desenvolvimento dessa atividade cognitiva.

Desse modo, categorizamos as informações - de acordo com sua natureza -, intentando que o produtor de texto, com auxílio da categorização, realize os processos referentes à identificação e ponderação de informações. As categorias de informação são as seguintes: 1 . Informação a partir de dado veiculado por fonte confiável; 2. Informação a partir de voz de especialista veiculada por fonte confiável; 3. Informação a partir de documento legal veiculado por fonte confiável; 4. Informação a partir de fato veiculado por fonte confiável; 5. Informação a partir de acontecimento; 6. Informação a partir de alusão histórica; 7. Informação a partir de ideal filosófico ou voz de especialista na área; e 8. Informação a partir de ideal sociológico ou voz de especialista na área. Para trabalhar com os participantes de pesquisa, em Arnemann (2020), essa categorização foi fundamental, a fim de auxiliá-los a identificar, na materialidade linguística dos textos, seus e dos outros, trechos que correspondem a informações.

Esclarecemos que essa categorização foi elaborada em um contexto científico. No entanto, como o objetivo se volta à utilização em outro contexto, a saber, a sala de aula escolar, conforme ocorreu em Arnemann (2020), realizamos o que Bernstein (1996) nomina como "recontextualização", ou seja, adaptamos de um contexto para outro, em nosso caso, a fim de conferir um caráter didático. Aqui, incorre-nos proceder uma explicação quanto ao processo de geração de dados junto aos participantes da pesquisa: durante os meses de junho a dezembro de 2018, o referido público produziu uma escrita diagnóstica, um artigo de opinião, duas redações do Exame Nacional do Ensino Médio e uma carta aberta, sendo essas produções realizadas, com exceção da diagnóstica (que teve somente uma versão), cada uma em três versões (escrita, 
PERcursos Linguísticos • Vitória (ES) •v. $11 \bullet$ n. 29 • 2021 • ISSN: 2236-2592 • Dossiê

temático $\bullet O$ texto na pesquisa e no ensino: conhecimentos, práticas e desafios na contemporaneidade •

reescrita e versão final). No intervalo entre as produções e entre as etapas de cada produção, desenvolvemos, junto aos discentes em questão, atividades de apoio, por meio das quais exploramos o trabalho com informações e subsidiamos o processo de escrita.

Dentre as atividades de apoio, uma das mais relevantes e que acompanhou todo o processo, com adaptações realizadas de acordo com a demanda, foi o Quadro de estratégias argumentativas, elaborado a partir das categorias de informação com a finalidade de auxiliar os estudantes a identificar informações e a percebê-las como um recurso essencial na construção da argumentação. Destarte, a seguir, resgatamos o referido instrumento didático:

Quadro 2 - Quadro para identificação de uso de estratégias argumentativas 
PERcursos Linguísticos • Vitória (ES) •v. 11 •n. 29 • 2021 • ISSN: 2236-2592 • Dossiê temático • O texto na pesquisa e no ensino: conhecimentos. práticas e desafios na contemporaneidade •

\begin{tabular}{|c|c|c|c|c|c|c|c|c|c|c|c|}
\hline \multirow{3}{*}{ 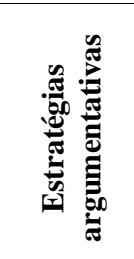 } & \multirow{2}{*}{\multicolumn{5}{|c|}{ Recursos }} & \multicolumn{6}{|c|}{ Estratégia argumentativa utilizada } \\
\hline & & & & & & \multicolumn{2}{|c|}{ Escrita } & \multicolumn{2}{|c|}{ Reescrita } & \multicolumn{2}{|c|}{ Versão final } \\
\hline & \multicolumn{5}{|c|}{ A ordem dos recursos pode variar } & $\begin{array}{l}\text { Marque com } \\
\text { um "x" a(s) } \\
\text { estratégia(s) } \\
\text { que você } \\
\text { usou }\end{array}$ & $\begin{array}{c}\text { Em qual(is) } \\
\text { linha(s) está? } \\
\text { Registre a } 1^{\mathrm{a} e} \text { a } \\
\text { última palavra } \\
\text { do trecho }\end{array}$ & $\begin{array}{l}\text { Marque com } \\
\text { um "x" a(s) } \\
\text { estratégia(s) } \\
\text { que você } \\
\text { usou }\end{array}$ & $\begin{array}{l}\text { Em qual(is) } \\
\text { linha(s) está? } \\
\text { Registre a } 1^{\mathrm{a} e} \text { a } \\
\text { última palavra } \\
\text { do trecho }\end{array}$ & \multirow{2}{*}{$\begin{array}{c}\text { Marque com } \\
\text { um "x" a(s) } \\
\text { estratégia(s) } \\
\text { que você } \\
\text { usou }\end{array}$} & $\begin{array}{c}\text { Em qual(is) } \\
\text { linha(s) está? } \\
\text { Registre a } 1^{\mathrm{a}} \mathrm{e} \\
\text { palavra última } \\
\text { do trecho }\end{array}$ \\
\hline $\begin{array}{l}\text { Estratégia } \\
\quad 1\end{array}$ & \multirow{5}{*}{$\begin{array}{l}\text { Informação a } \\
\text { partir de }\end{array}$} & + & $\begin{array}{l}\text { dados de pesquisas } \\
\text { com fonte confiável }\end{array}$ & + & \multirow{5}{*}{$\begin{array}{l}\text { desenvolvimento de } \\
\text { argumento }\end{array}$} & & & & & & \\
\hline $\begin{array}{c}\text { Estratégia } \\
2\end{array}$ & & + & $\begin{array}{c}\text { voz de especialista } \\
\text { veiculada por fonte } \\
\text { confiável }\end{array}$ & + & & & & & & & \\
\hline $\begin{array}{l}\text { Estratégia } \\
\quad 3\end{array}$ & & + & documento legal & + & & & & & & & \\
\hline $\begin{array}{c}\text { Estratégia } \\
4\end{array}$ & & + & $\begin{array}{c}\text { exemplo (fato } \\
\text { veiculado por fonte } \\
\text { confiável) }\end{array}$ & + & & & & & & & \\
\hline $\begin{array}{c}\text { Estratégia } \\
5\end{array}$ & & + & $\begin{array}{c}\text { exemplo } \\
\text { (acontecimento } \\
\text { corriqueiro) }\end{array}$ & + & & & & & & & \\
\hline $\begin{array}{c}\text { Estratégia } \\
6\end{array}$ & $\begin{array}{l}\text { Informação a } \\
\text { partir de } \\
\text { alusão } \\
\text { histórica } \\
\end{array}$ & + & $\begin{array}{l}\text { desenvolvimento de } \\
\text { argumento }\end{array}$ & + & $\begin{array}{l}\text { informações ou fatos } \\
\text { veiculados por fonte } \\
\text { confiável }\end{array}$ & & & & & & \\
\hline $\begin{array}{c}\text { Estratégia } \\
7\end{array}$ & $\begin{array}{l}\text { Informação a } \\
\text { partir de } \\
\text { ideal } \\
\text { filosófico/ } \\
\text { sociológico } \\
\text { ou voz de } \\
\text { especialista } \\
\end{array}$ & + & $\begin{array}{l}\text { desenvolvimento de } \\
\text { argumento }\end{array}$ & + & $\begin{array}{l}\text { informações veiculadas por } \\
\text { fonte confiável } \\
\text { ou } \\
\text { acontecimentos corriqueiros }\end{array}$ & & & & & & \\
\hline $\begin{array}{c}\text { Estratégia } \\
8\end{array}$ & \multirow[b]{3}{*}{$\begin{array}{l}\text { Apresentação } \\
\text { de contra- } \\
\text { argumento }\end{array}$} & & + & & \multirow{2}{*}{$\begin{array}{l}\text { desenvolvimento de } \\
\text { argumento }\end{array}$} & & & & & & \\
\hline $\begin{array}{c}\text { Estratégia } \\
9\end{array}$ & & + & $\begin{array}{l}\text { a partir de dados de } \\
\text { pesquisas por fonte } \\
\text { confiável }\end{array}$ & + & & & & & & & \\
\hline $\begin{array}{c}\text { Estratégia } \\
10\end{array}$ & & + & $\begin{array}{l}\text { exemplo (fato } \\
\text { abordado em fonte } \\
\text { confiável ou } \\
\text { acontecimento } \\
\text { corriqueiro) }\end{array}$ & + & $\begin{array}{c}\text { desenvolvimento de } \\
\text { argumento } \\
+ \\
\text { exemplo (fato abordado em } \\
\text { fonte confiável ou } \\
\text { acontecimento corriqueiro } \\
\text { para corroborar a voz do } \\
\text { autor da redação do ENEM) }\end{array}$ & & & & & & \\
\hline Outra est & D & & & & & & & & & & \\
\hline
\end{tabular}

Fonte: Arnemann (2020, p. 401). 


\section{PERcursos Linguísticos • Vitória (ES) •v. 11 •n. 29 • 2021 • ISSN: 2236-2592 • Dossiê temático $\bullet O$ texto na pesquisa e no ensino: conhecimentos, práticas e desafios na contemporaneidade •}

Tal quadro, empregado pelos participantes do estudo nos processos de produção do artigo de opinião, das redações do ENEM e da carta aberta, foi desenvolvido no contexto de pesquisa de Arnemann (2020) e revelou ser um instrumento didático que pode subsidiar tanto o docente quanto o discente no processo de escrita argumentativa. Diante dessa efetividade, asseveramos que tal quadro pode ser utilizado em sala de aula, com adaptações, se necessário, e de acordo com o contexto. Além do mais, defendemos que o processo de escrita não envolve somente o registro escrito; outros momentos - que têm ficado à margem, por inúmeras razões - podem exercer diferença crucial. No caso do instrumento didático em questão, verificamos que pode auxiliar o estudante a se familiarizar com as noções de informação, estratégia e argumentação - com vistas a internalizá-las - mediante o contato com o concreto, ou seja, por meio da identificação na materialidade linguística do (seu) texto, o que, por conseguinte, pode operar no exercício ativo do estudante, enquanto um sujeito que percebe como e de que se compõe seu texto.

Além do Quadro de estratégias argumentativas - que se inscreve como uma proposta didática efetiva -, outros elementos relativos à informatividade demandam atenção e, também, podem ser recontextualizados para a situação de ensino. Um deles se refere à definição do que é novo e do que é dado. Assim, ressaltamos que, antes de trabalharmos com conceitos mais elaborados, exploramos aqueles de natureza mais concreta e próxima à realidade dos discentes da turma $3^{\circ} \mathrm{C}$. Essa ação tem a função de realizar a mediação entre os conhecimentos cotidianos que os estudantes já têm e os conhecimentos escolarizados/científicos, com base em Vygotsky (1991, 2009). Em Arnemann (2020), isso se efetivou por meio do trabalho com o que o estudante já conhece, a noção de "dado", e o que ainda não conhece, a noção de "novo" no texto do outro. Para auxiliar os terceiranistas em cena no registro do que consideram dado ou novo, elaboramos o seguinte quadro:

Quadro 3 - Levantamento de informações (novas e dadas) na produção textual

\begin{tabular}{|c|c|c|c|c|c|}
\hline Texto & $\begin{array}{l}\text { Número de } \\
\text { informações } \\
\text { observadas }\end{array}$ & $\begin{array}{l}\text { As informações novas } \\
\text { tornam os textos mais } \\
\text { interessantes, pelo caráter } \\
\text { de novidade. Essas } \\
\text { informações apresentam } \\
\text { uma imprevisibilidade }\end{array}$ & $\begin{array}{l}\text { Em relação ao seu artigo de } \\
\text { opinião, você empregou } \\
\text { informações? Registre a } \\
\text { informação que você } \\
\text { empregou no espaço } \\
\text { referente ao texto e ao } \\
\text { caráter "novas" ou "dadas". }\end{array}$ & $\begin{array}{l}\text { Para que } \\
\text { você } \\
\text { empregou a } \\
\text { informação } \\
\text { em seu } \\
\text { texto? }\end{array}$ & $\begin{array}{l}\text { Você } \\
\text { entende } \\
\text { que } \\
\text { atingiu } \\
\text { seu } \\
\text { objetivo? } \\
\text { Por quê? }\end{array}$ \\
\hline Texto 1 & Novas & informações dadas. & & & \\
\hline
\end{tabular}




\section{PERcursos Linguísticos • Vitória (ES) •v. 11 •n. 29 • 2021 • ISSN: 2236-2592 • \\ Dossiê temático $\bullet O$ texto na pesquisa e no ensino: conhecimentos, práticas e desafios na contemporaneidade •}

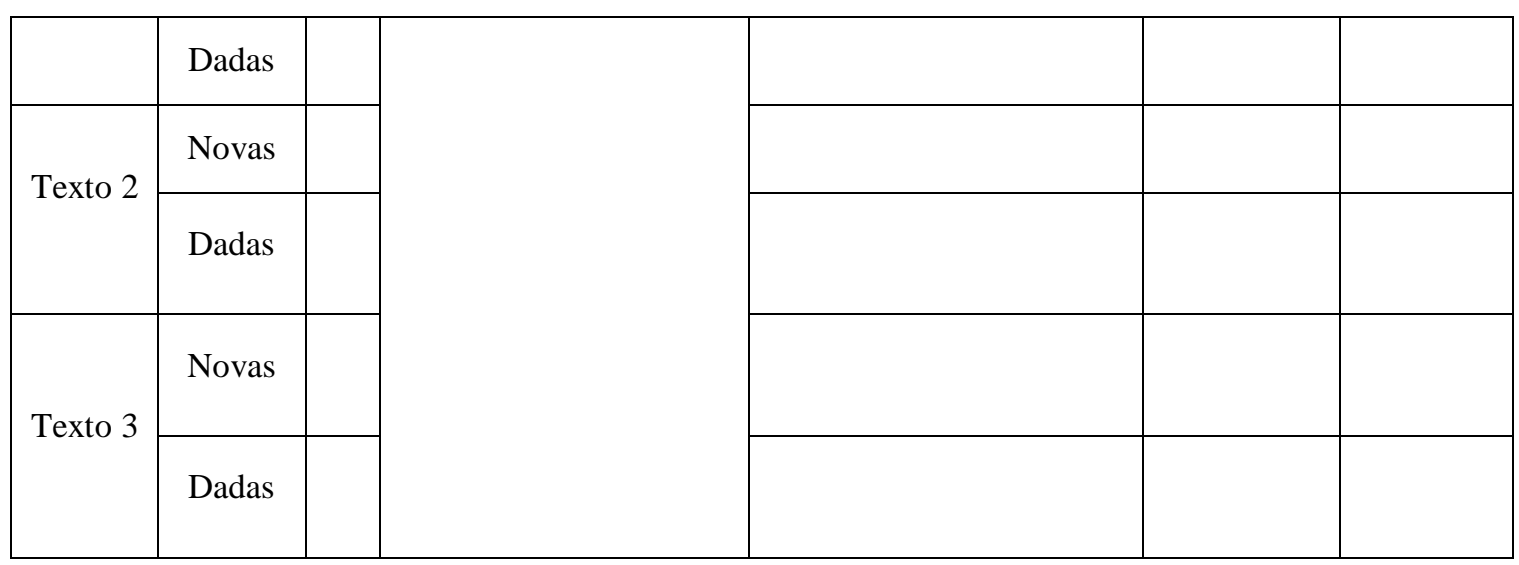

Fonte: Arnemann (2020, p. 376).

Esse quadro foi empregado como atividade de apoio na segunda produção textual realizada pelos participantes da pesquisa, na qual receberam uma proposta de redação do ENEM com quatro textos motivadores e foram convidados a identificar o que já conheciam e o que não conheciam nesses textos. $\mathrm{O}$ uso desse quadro, dentre outras funções, visa auxiliar o estudante a desmistificar o tabu que é construído em relação aos textos motivadores e/ou de apoio da redação do ENEM: são de difícil compreensão e de difícil processamento. Queremos defender, com tal asserção, que os textos não são, de todo, de difícil compreensão, o que está em falta são subsídios que o discente tem para auxiliar no processamento textual. É diante dessa ausência que inúmeros estudantes (e até alguns docentes) se agarram à ilusão de que, para ter um bom desempenho na redação do ENEM, precisam saber o tema antes. Esse quadro opera no contato do estudante com o texto e o exercício do registro o convida a desenvolver a atenção voluntária e a memória. Em relação a essa última, acentuamos seu papel, o qual nos termos de Vygotsky (1991, p.38), é "lembrar ativamente com a ajuda de signos".

A realização dessa atividade de apoio viabilizou a aproximação dos participantes da pesquisa com os textos motivadores, por meio da identificação do que consideraram novidade e o que já conheciam, favorecendo a autoidentificação (discente) sobre o que compõe seu texto. Realizado esse contato inicial com as noções de "dado", "novo" e informação, para as produções textuais seguintes, elaboramos outro quadro, o qual explora a informação de modo mais aprofundado e mais articulado ao processo de escrita argumentativa, convidando o estudante a avaliar como está trabalhando com a informação em sua própria produção. O quadro consta, a seguir, e expõe o tema da redação do ENEM que foi realizada na segunda produção textual com três momentos de escrita:

Quadro 4 - Quadro autoavaliativo sobre o processo de produção textual 
PERcursos Linguísticos • Vitória (ES) •v. 11 •n. 29 • 2021 • ISSN: 2236-2592 • Dossiê temático • O texto na pesquisa e no ensino: conhecimentos, práticas e desafios na contemporaneidade •

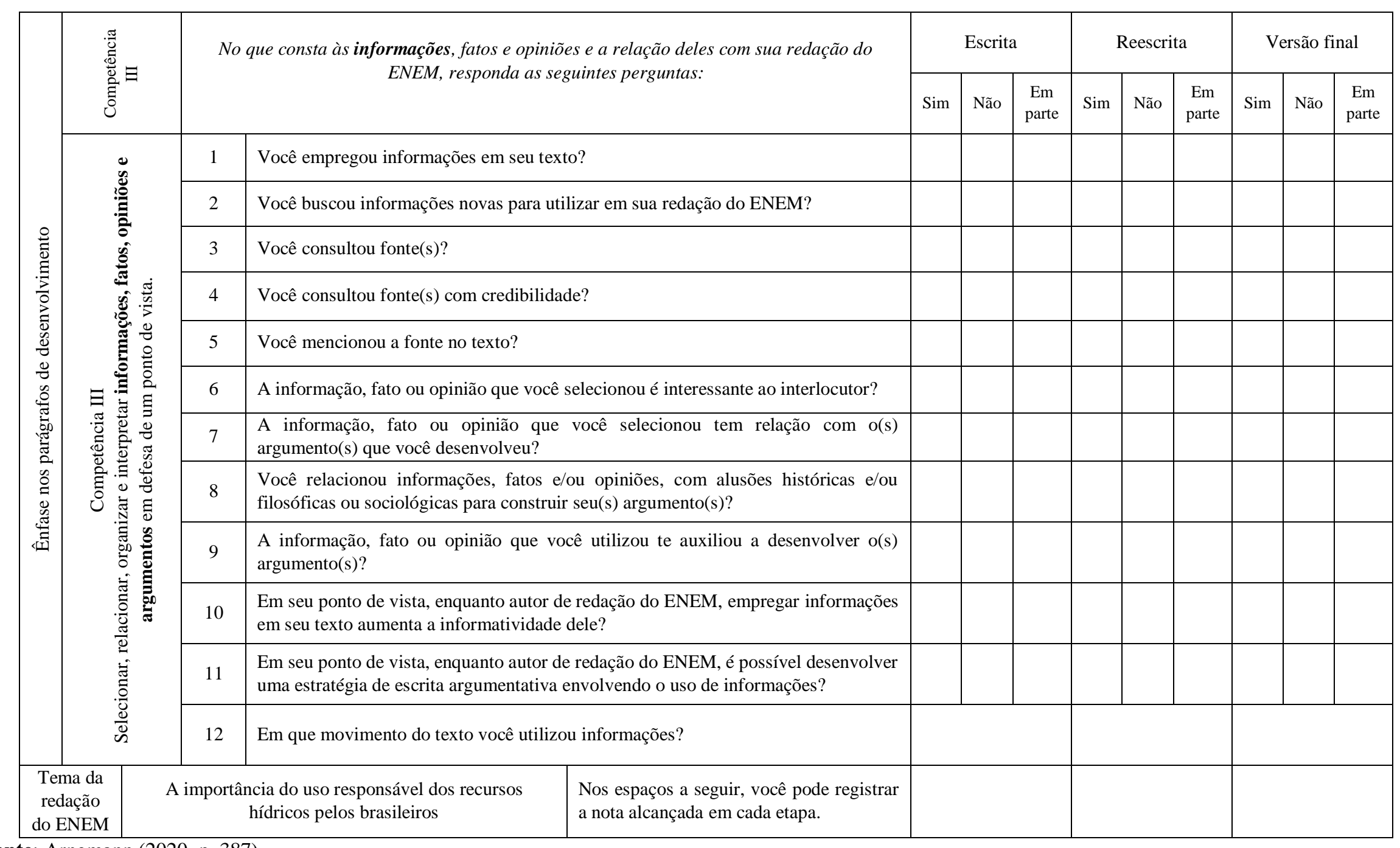

Fonte: Arnemann (2020, p. 387). 


\section{PERcursos Linguísticos • Vitória (ES) •v. 11 •n. 29 • 2021 • ISSN: 2236-2592 • Dossiê temático $\bullet O$ texto na pesquisa e no ensino: conhecimentos, práticas e desafios na contemporaneidade •}

Por intermédio dessa atividade de apoio, o estudante é convidado a se autoavaliar no que diz respeito a cada um dos momentos de escrita de sua produção, podendo, em cada um deles, realizar uma espécie de checklist (perguntas 1 a 5 , principalmente) sobre os elementos constitutivos da redação do ENEM, além de refletir (perguntas 6 a 12, especialmente) acerca do uso da informação em sua escrita argumentativa. É conferida ênfase à Competência III (item de avaliação da redação do ENEM), uma vez que se concentra no movimento referente ao desenvolvimento dos argumentos, portanto, estágio do texto que pode requerer maior uso de informações.

Após elucidarmos três atividades de apoio (Quadros 2, 3 e 4) que foram utilizadas pelos participantes de pesquisa, dedicamo-nos à exploração de quadros desenvolvidos no contexto de análise dos dados da pesquisa de Arnemann (2020) que podem ser recontextualizados para uso em sala de aula. Nesse momento, então, voltamo-nos à discussão das noções de "dado" e "novo", posto que as definições que assumimos foram fundamentais para a apreciação analítica e, por conseguinte, para os quadros que exploramos, a posteriori.

Convém pontuar que diferentemente de Beaugrande e Dressler (1981), que propuseram o critério de informatividade analisando um gênero textual da esfera expositiva, estudamos o uso da informatividade em sala de aula em gêneros textuais do campo argumentativo. Temos, aqui, uma distinção não apenas nos gêneros, como também nos (possíveis) interlocutores. Assim, ressaltamos que o produtor de texto argumentativo visa convencer o interlocutor a aderir a sua tese.

Beaugrande e Dressler (1981) dispõem que na oralidade, com recursos de entonação, comumente os falantes apresentam uma informação dada no início - estabelecendo um vínculo comunicativo com o ouvinte - e, ao final, apresentam a informação nova, ou seja, a novidade. $\mathrm{Na}$ esteira da argumentação escrita, isso pode ocorrer de modo similar, com as exceções de deslocamentos sintáticos aceitos em cada língua, as quais podem trazer uma informação nova para o início de uma oração e uma já conhecida ao final. Os teóricos em cena arguem que essa disposição entre o dado e o novo configura uma das cinco fontes de expectativa humana ${ }^{6}$ que propuseram, a qual diz respeito à sinalização da informatividade. Em nosso estudo, foi primordial definir o que corresponde à informação nova e o que corresponde à informação dada diante do contexto de escrita argumentativa escolar. Nesse sentido, focalizamos os termos "dado" e "novo" e, quanto àquele, dispomos que os

\footnotetext{
${ }^{6}$ Para conhecimento das outras quatro e da atualização teórica, consultar Arnemann (2020).
} 


\title{
PERcursos Linguísticos • Vitória (ES) •v. 11 •n. 29 • 2021 • ISSN: 2236-2592 • Dossiê temático $\bullet O$ texto na pesquisa e no ensino: conhecimentos, práticas e desafios na contemporaneidade •
}

elementos que o interlocutor já conhece são apresentados no início da oração, pois se referem ao conteúdo e/ou tema do texto em questão. Agora, o que é dito sobre esse conteúdo e/ou tema é apresentado ao fim da oração. Nesse viés, consideramos como "dado" o tema e/ou o conteúdo - apresentado no início da oração - pois são informações já de conhecimento ou mais previsíveis ao interlocutor, visto que é o que está em cena na interação verbal e, amiúde, é apresentado no texto ou enunciado que mobiliza a produção do texto em curso ou, ainda, na situação comunicativa em vigência (ARNEMANN, 2020, p. 60).

Ao passo que

\begin{abstract}
entendemos como "novo" o que é dito sobre o tema e/ou conteúdo, pois é aí que reside o caráter de novidade ao interlocutor: o que de novo, nessa situação comunicativa, pode ser dito sobre o tema, portanto está localizado ao fim da oração. O que é dito de novo em relação ao tema apresentado, diz respeito à informação que é selecionada e registrada na materialidade linguística. Ainda, consideramos como novo a interpretação que o interlocutor realiza acerca da informação que apresenta, pois se espera que em um texto do campo argumentativo não apenas tragam-se informações novas sobre o tema que é posto em questão, mas, e sobretudo, o que essas informações estão revelando ao interlocutor (ARNEMANN, 2020, p. 60).
\end{abstract}

Ao definirmos o que compreendemos como "novo", propomos que essa noção pode assumir duas classificações: a segunda, voltada à apresentação da informação nova, e a primeira, contemplando a apresentação e acrescentando a interpretação da informação. Essa classificação desempenha uma função muito relevante na identificação, tanto por parte de quem pesquisa, de quem ensina ou de quem aprende sobre a escrita argumentativa, visto que auxilia a demarcar, na materialidade linguística do texto, até que ponto o autor está apresentando uma informação e em que ponto passa a realizar a interpretação, ou seja, a registrar o que tal informação revela ou, ainda, auxilia a verificar que a interpretação não foi contemplada.

Concebemos esse ponto de vista para trabalhar com as informações novas no texto, pois, na imensa maioria dos casos, somente a apresentação da informação não é suficiente para conferir argumentatividade ao texto. Em consonância com Perelman e Olbrechts-Tyteca (2014), a informação é essencial para constituir a argumentação.

Nesse viés, para operar a identificação do que é dado e do que corresponde ao novo no interior de um parágrafo, buscamos apoio, também, em Charaudeau (2014), que dispõe acerca da organização do modo argumentativo e assevera que a argumentação se desenvolve mediante a seguinte organização: inicia com uma asserção de partida (A1), que é o ponto de partida, com vistas a chegar a uma asserção de chegada (A2), que é o fechamento da argumentação. Todavia, o autor explica que nem sempre é possível que se instaure uma argumentação efetiva com somente essas duas asserções. Por vezes, é necessário tecer uma asserção de passagem (Ap), a qual tem a função de estabelecer uma relação entre o ponto de partida e o ponto de chegada, de 


\section{PERcursos Linguísticos • Vitória (ES) •v. 11 •n. 29 • 2021 • ISSN: 2236-2592 • Dossiê temático $\bullet O$ texto na pesquisa e no ensino: conhecimentos, práticas e desafios na contemporaneidade •}

modo convincente. Em muitos casos, é na asserção de passagem que se inscrevem os exemplos e/ou ilustrações que o autor do texto busca para sustentar sua argumentação.

Assim, empregamos a classificação de Charaudeau (2014) para auxiliar na identificação do que corresponde ao dado e o que representa o novo, o que culminou na elaboração do quadro subsequente (P2 corresponde ao segundo parágrafo e P3 ao terceiro parágrafo):

Quadro 5 - Quadro para sinalização da informatividade

\begin{tabular}{|c|c|c|c|c|c|}
\hline \multicolumn{6}{|c|}{ Produção x } \\
\hline \multirow{2}{*}{ 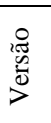 } & \multicolumn{2}{|c|}{ Ordem } & \multirow{2}{*}{$\begin{array}{l}\text { Início da oração - } \\
\text { apresentação do tema }\end{array}$} & \multirow{2}{*}{ Verbo } & \multirow{2}{*}{ Fim da oração - o que é dito sobre o tema } \\
\hline & $\mathrm{P}$ & A & & & \\
\hline & \multirow{3}{*}{$\mathrm{P} 2$} & A1 & & & \\
\hline & & Ap & & & \\
\hline & & $\mathrm{A} 2$ & & & \\
\hline & \multirow{3}{*}{ P3 } & A1 & & & \\
\hline & & Ap & & & \\
\hline & & $\mathrm{A} 2$ & & & \\
\hline
\end{tabular}

Fonte: Arnemann (2020, p. 156).

No contexto de investigação, esse quadro, além da identificação do que é dado e do que é novo, conferiu base para asseverarmos que:

os trechos que correspondem à informação dada apresentam o tema que será discutido, o qual advém da proposta de produção textual, podendo ser o tema em si ou uma especificação dele. Isso ocorre nas asserções de partida, especialmente no parágrafo 2, pois em alguns casos a apresentação do tema tem natureza anafórica, ou seja, recupera o que foi apresentado ao fim ou ao longo da asserção anterior ou, ainda, no decorrer do parágrafo, como é o caso de algumas asserções de chegada (ARNEMANN, 2020, p. 253).

Diante disso, entendemos que esse quadro pode ser utilizado em sala de aula, haja vista que configura um instrumento didático capaz de viabilizar a identificação, na materialidade linguística do texto, do dado e do novo e a observação da articulação entre os dois ao longo das asserções. Isso, por sua vez, propicia verificar se o texto está circular/redundante ou se está progredindo em termos de apresentação de novas informações, tanto no sentido de inserção de novos elementos quanto no desenvolvimento e delineamento dos já expostos.

Ainda, em se tratando somente do "novo", tal quadro pode subsidiar em sua classificação, ou seja, a identificar se a informação é somente apresentada ou se é apresentada e interpretada. Todavia, cabe expor que a classificação, metaforicamente, é apenas "a porta de 


\section{PERcursos Linguísticos • Vitória (ES) •v. 11 •n. 29 • 2021 • ISSN: 2236-2592 • Dossiê temático $\bullet O$ texto na pesquisa e no ensino: conhecimentos, práticas e desafios na contemporaneidade •}

entrada" para a realização de outras operações. Ao somente apresentar uma informação e identificar que apenas essa etapa foi realizada, o estudante (autor do texto) e o docente têm o diagnóstico de que a argumentação pode não ter sido contemplada com suficiência, pois a informação não foi explorada. Isso implica uma ausência de sinalização acerca do que o autor deseja explorar com aquela informação, ou seja, o que ela está revelando. Desse modo, a argumentação fica fragilizada, pois a exploração dos elementos necessários para o interlocutor aderir à tese proposta pelo autor do texto está incompleta.

Esse diagnóstico é fundamental para a corresponsável tomada de decisões em relação ao texto, ou seja, docente e discente necessitam encontrar estratégias para desenvolver a interpretação da informação. Tal processo não é simples, uma vez que o desenvolvimento da interpretação não depende apenas de habilidades e de prática de escrita. Além disso, necessita dos conhecimentos enciclopédicos, textuais, linguísticos e interacionais do sujeito em situação de aprendizagem.

Ainda, elaboramos outro quadro, com vistas a identificar quais categorias de informação constam nos textos dos sujeitos da pesquisa em pauta. Para tal, depreendemos como fundamental observar a origem das informações apresentadas. Desse modo, organizamos um quadro que permite registrar o trecho em que uma informação se apresenta no texto do estudante e o excerto correspondente no texto base empregado, o que viabiliza que se tenha, em um mesmo plano visual, ambos os registros. A seguir, resgatamos o quadro:

Quadro 6 - Quadro para identificação da fonte e categoria das informações

\begin{tabular}{|c|c|c|c|c||}
\hline \hline & $\begin{array}{c}\text { 1.Informação a partir de dado } \\
\text { veiculado por fonte confiável }\end{array}$ & $\begin{array}{c}\text { 2.Informação a partir de voz } \\
\text { de especialista veiculada por } \\
\text { fonte confiável }\end{array}$ & $\begin{array}{c}\text { 3.Informação a partir de } \\
\text { documento legal veiculado } \\
\text { por fonte confiável }\end{array}$ \\
$\begin{array}{c}\text { 4.Informação a partir de fato } \\
\text { veiculado por fonte confiável }\end{array}$ & $\begin{array}{c}\text { 5.Informação a partir de } \\
\text { acontecimento }\end{array}$ & $\begin{array}{c}\text { 6.Informação a partir de } \\
\text { alusão histórica }\end{array}$ \\
\hline $\begin{array}{c}\text { 7.Informação a partir de ideal filosófico } \\
\text { ou voz de especialista na área }\end{array}$ & $\begin{array}{c}\text { 8.Informação a partir de ideal sociológico ou voz } \\
\text { de especialista na área }\end{array}$ \\
\hline Parágrafo 2 na íntegra & Trechos dos textos base utilizados & Categoria \\
\hline Parágrafo 3 na íntegra & Trechos dos textos base utilizados & Categoria \\
\hline
\end{tabular}

Fonte: Arnemann (2020, p. 153).

Por meio desse quadro, pudemos realizar verificação entre o texto produzido pelos sujeitos de pesquisa e o texto base em que buscaram a informação. Esse procedimento auxiliou a identificar a categoria da informação, pois elementos externos à informação apresentada e/ou 


\section{PERcursos Linguísticos • Vitória (ES) •v. 11 •n. 29 • 2021 • ISSN: 2236-2592 • Dossiê temático $\bullet O$ texto na pesquisa e no ensino: conhecimentos, práticas e desafios na contemporaneidade •}

interpretada no texto do discente também requerem ser observados. Tal quadro nos forneceu base para subsidiar a observação de como as informações são recuperadas pelos sujeitos de pesquisa: por meio de paráfrase ou de alusão. Nos momentos em que verificamos a ocorrência de paráfrase, observamos um desenvolvimento mais restrito da interpretação da informação, o que indicia que o autor do texto está concentrado na fase de apresentação da informação. Já nas ocasiões em que observamos a ocorrência de alusão, percebemos que o autor do texto se dedicou (mais) a interpretar a informação que trouxe. Em termos espaciais, ao realizar uma alusão, que concerne a uma referência mais pontual e concisa acerca da informação, o produtor de texto dedica mais espaço à exposição de seu ponto de vista sobre a informação, o que, por conseguinte, favorece a manifestação da "voz autoral", muito importante em textos de natureza argumentativa.

Assim, tal quadro também pode ser utilizado em sala de aula como um instrumento didático, auxiliando inclusive no combate ao plágio, o qual não foi abordado na tese por não ter se manifestado nos textos dos participantes da pesquisa. Desse modo, tanto em relação ao Quadro 6 como ao Quadro 5, ajuizamos que o uso de ambos pode necessitar ou não de recontextualização, sendo esse ponto definido de acordo com os contextos de ensino e de aprendizagem. Estimamos que a adaptação pode contemplar uso tanto na Educação Básica como no Ensino Superior, em espaços cujo objetivo seja o ensino de produção textual argumentativa.

\section{Considerações finais}

Os desafios encontrados por pesquisadores, professores e estudantes em relação ao texto são inúmeros e de naturezas distintas, até porque o texto é um fenômeno resultante das interações humanas. Em meio a esse imenso "palheiro" (o universo do texto), encontramos uma "agulha", aqui representada pelos quadros - elaborados a partir do critério de informatividade -, que podem ser considerados como instrumentos e propostas didáticas para subsidiar o processo de escrita argumentativa.

Com base nessa analogia, percebemos que a construção de percursos linguísticos que aproximem teoria(s) e metodologia(s) pode exigir um trabalho cansativo, ardiloso e minucioso, principalmente por parte de pesquisadores professores, mas não é impossível. No momento em que a agulha é encontrada e pode servir como instrumento por aqueles que estão ávidos pelo saber - os estudantes -, os mais belos, fortes, criativos - dentre tantas outras atribuições tecidos podem ser construídos. Tecidos, nesse escopo, referem-se a textos. 


\section{PERcursos Linguísticos • Vitória (ES) •v. 11 •n. 29 • 2021 • ISSN: 2236-2592 • Dossiê temático $\bullet O$ texto na pesquisa e no ensino: conhecimentos, práticas e desafios na contemporaneidade •}

Aqui, é oportuno mencionar que a maioria dos participantes da pesquisa em pauta, hoje, encontra-se cursando uma graduação em uma universidade pública. Eles são sujeitos ativos que perceberam a realização de uma pesquisa de doutorado, na aula de Língua Portuguesa, em parceira com o professor titular, como uma oportunidade não somente de aprimorar a escrita argumentativa, mas, sobretudo, de promover mudanças de vida por meio do uso pertinente e adequado de informações em textos de natureza argumentativa.

Trazemos essa informação a fim de expor que os quadros discutidos neste estudo alguns já utilizados pelos estudantes e outros no aguardo por esse momento - são o resultado de articulações teórico-metodológicas e se configuram como instrumentos e propostas didáticas. Entretanto, a efetividade que defendemos que possuem se deve, também, ao trabalho corresponsável realizado entre os envolvidos: pesquisadora professora, professor titular e a turma $3^{\circ} \mathrm{C}$. Com isso, queremos lembrar que um dos desafios que pesquisadores, professores e estudantes de texto precisam superar diz respeito ao trabalho em parceira, pois é ela que permite que teoria e prática se encontrem e, por conseguinte, que aspectos teórico-metodológicos possam sustentar o desenvolvimento de propostas didáticas efetivas, tal como se configuram os quadros que discutimos neste artigo.

Por fim, registramos que o universo de pesquisa a nossa frente é bem amplo, muitas lacunas ainda se inscrevem no que diz respeito à informatividade, por exemplo. Aqui, esse critério de textualidade foi explorado como base para elaboração de instrumentos didáticos que podem subsidiar a escrita argumentativa. Pensando na esfera argumentativa, ainda é necessário investigar a informatividade nos gêneros textuais orais e multissemióticos, os quais carecem de propostas didáticas que viabilizem os processos de ensino e aprendizagem.

\section{Referências}

ARNEMANN, A. R. Informatividade da sala de aula: o emprego de informações na construção de argumentos. 2010, 438 p. (Doutorado em Estudos Linguísticos) - Universidade Federal de Santa Maria, RS, 2020.

BERNSTEIN, B. A estruturação do discurso pedagógico: classe, códigos e controle. Petrópolis: Vozes, 1996.

BEAUGRANDE, R. de.; DRESSLER, W. Introduction to Text Linguistics. New York: Longman, 1981.

BOM CAMILLO, L. A Teoria Holística da Atividade e a constituição do papel docente na formação inicial do educador linguístico. 2017, 169 p. (Doutorado em Estudos Linguísticos) - Universidade Federal de Santa Maria, RS, 2017. 


\section{PERcursos Linguísticos • Vitória (ES) •v. 11 •n. 29 • 2021 • ISSN: 2236-2592 • Dossiê temático $\bullet O$ texto na pesquisa e no ensino: conhecimentos, práticas e desafios na contemporaneidade •}

BOM CAMILLO, L. A constituição docente na formação inicial e a escuta supervisiva com base na Teoria Holística da Atividade. Revista Linguagens \& Cidadania. Santa Maria, n. 26, 2014. Disponível em: 〈https://periodicos.ufsm.br/LeC/article/view/v〉. Acesso em: 19 fev. 2020 .

BURNS, A. Doing Action Research in English Language Teaching: a gruide for practitioners. New York: Routledge, 2010.

CHARAUDEAU, P. Linguagem e discurso: modos de organização. Vários tradutores. 2 ed. 2 imp. São Paulo: Contexto, 2014.

DOLZ, J.; NOVERRAZ, M. SCHNEUWLY, B. Sequências didáticas para o oral e a escrita: apresentação de um procedimento. In: SCHNEUWLY, B.; DOLZ, J. Gêneros orais e escritos da escola. Tradução de Roxane Rojo e Glaís Sales Cordeiro. Campinas: Mercado de Letras, 2004, p. 81-108.

DOLZ, J. SCHNEUWLY, B. Os gêneros escolares - Das práticas de linguagem aos objetos de ensino. In: SCHNEUWLY, B.; DOLZ, J. Gêneros orais e escritos da escola. Tradução de Roxane Rojo e Glaís Sales Cordeiro. Campinas: Mercado de Letras, 2004, p. 61-80.

FREIRE, P.; FAUNDEZ, A. Por uma Pedagogia da Pergunta. 3. ed. Rio de Janeiro: Paz e Terra, 1985.

FREITAG, F.; RICHTER, M. G. Diálogos com Felipe Freitag: entrevista com o criador da Teoria Holística da Atividade, Marcos Gustavo Richter. IV Fórum de Estudos Interacionistas. UFSM, 2015. (Entrevista transcrita; material inédito).

KOCH, I. V.; ELIAS, V. M. Ler e escrever: estratégias de produção textual. 2. ed. 2 reimp. São Paulo: Contexto, 2014.

LURIA, A. R. Fundamentos de Neuropsicologia. Tradução de Juarez Aranha Ricardo. São Paulo: Editora da Universidade de São Paulo, 1981.

RICHTER, M. G. Aquisição, representação e atividade. Santa Maria: UFSM/PPGL-Editores, 2008.

PERELMAN, C.; OLBRECHTS-TYTECA, L. Tratado da Argumentação: A Nova Retórica. Tradução de Maria Ermantina de Almeida Prado Galvão. 3. ed. São Paulo: Martins Fontes, 2014.

THIOLLENT, M. Metodologia da Pesquisa-Ação. 18. ed. São Paulo: Cortez, 2011.

VYGOTSKY, L. S. A formação social da mente. 4. ed. bras. São Paulo: Martins Fontes, 1991.

VYGOTSKY, L. S. A construção do pensamento e da linguagem. 2. ed. Tradução de Paulo Bezerra. São Paulo: Martins Fontes, 2009. 